\title{
REVISTA
}

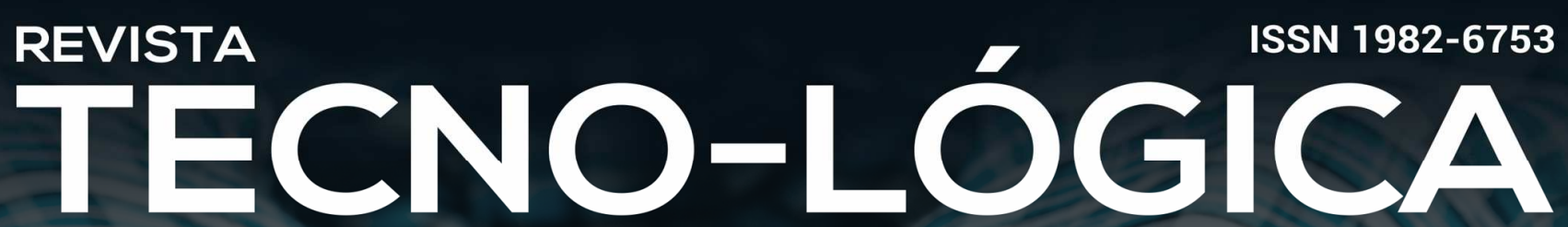

Edição Especial com publicação de trabalhos selecionados do V SIGEPRO

\section{IMPACTO DA MUDANÇA DE ESTRATÉGIA NA GESTÃO DE PROJETOS: ESTUDO DE CASO EM UMA EMPRESA DO RAMO PETROQUÍMICO}

\author{
Maicon Carvalho de Borba ${ }^{1}$, Débora Oliveira da Silva ${ }^{2}$, Jocieli Francisco da Silva ${ }^{2 *}$, Flávia Luana da Silva ${ }^{2}$ \\ ${ }^{1}$ Graduação em Engenharia de Produção, Universidade do Vale do Rio dos Sinos (UNISINOS), 93022-750, São Leopoldo, Brasil. \\ 2 Programa de Pós-Graduação em Engenharia de Produção e Sistemas, Universidade do Vale do Rio dos Sinos (UNISINOS), 93022- \\ 750, São Leopoldo, Brasil.
}

*E-mail: jocielifs@outlook.com

Recebido em:17/09/2020

\section{RESUMO}

A busca por competitividade e inovação se torna algo cada vez mais importante no cenário atual. Comumente, Gestão de Projetos e Planejamento Estratégico atuam associados nas organizações, e o desalinhamento entre as partes pode originar resultados improdutivos. Mudanças estratégicas se tornam necessárias quando o cenário competitivo direciona para novas oportunidades de mercado, porém, planos anteriores estão em desenvolvimento e a adaptação correta busca provocar o menor impacto entre a Gestão de Projetos e Mudança. O objetivo do trabalho é analisar os impactos que a mudança de estratégia de uma organização traz para a gestão de projetos. Para isso, foi realizado um estudo de caso em uma empresa do ramo químico e petroquímico. Através desta pesquisa, foi possível identificar os impactos que a mudança de estratégia causa na gestão de projetos em uma organização e as abordagens utilizadas para minimizar os efeitos negativos. Reuniões periódicas, análise do objetivo do projeto ao final de cada etapa do pipeline e estudo da compatibilidade do projeto em relação à estratégia são abordagens utilizadas pela empresa para minimizar os impactos. Problemas relacionados a atraso no prazo de entrega, reprogramação de equipes, cumprimento de metas das equipes de processo e custos são características afetadas pela mudança de estratégia.

Palavras-chave: Gestão de Projetos. Gestão de Portfólio. Planejamento Estratégico. Projetos Estratégicos.

\section{Introdução}

O planejamento estratégico pode ser definido como uma série de ações que possuem relação entre si, com o intuito de conduzir a organização a um resultado favorável [1]. As revisões desse planejamento são um instrumento necessário para analisar a competitividade e a situação do mercado [2]. Através das estratégias, as organizações definem os objetivos a serem alcançados, com intuito de sobrevivência no mercado, sustentabilidade e adequação aos cenários decorrentes de suas práticas empresariais [3]. A busca por competitividade nas empresas é responsável, muitas vezes, por mudanças no planejamento estratégico, buscando constantemente a inovação como foco principal [4]. 


\section{REVISTA}

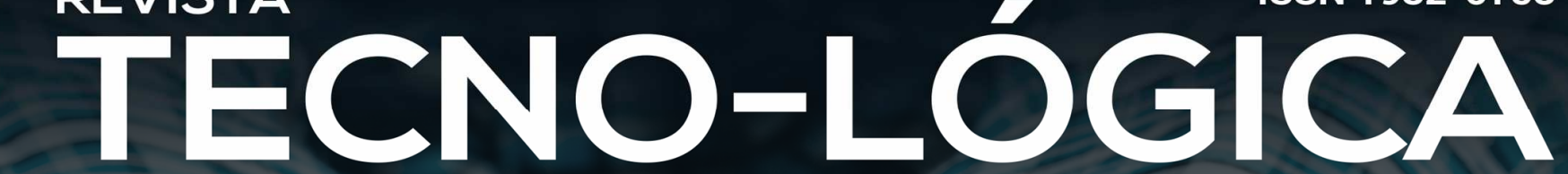

Edição Especial com publicação de trabalhos selecionados do V SIGEPRO

O cumprimento da estratégia envolve uma série de ações e projetos que influenciam no desempenho de toda organização [3]. Os projetos são utilizados como ferramenta para alcançar os objetivos de mercado das organizações, principalmente na área de inovação [5]. A mudança de estratégia das empresas em relação à inovação utiliza as técnicas de gestão de projetos como ferramenta principal para implantar o planejamento, sendo considerada parte importante do sucesso [6]. A gestão de projetos em conjunto com o alinhamento estratégico auxilia no direcionamento de priorização de projetos que realmente trarão benefícios para o negócio. A partir do planejamento estratégico, as organizações utilizam a gestão de projetos como meio de busca dos objetivos [7].

A sobrevivência das empresas no mercado está atrelada a estratégia de mudanças constantes, conforme oportunidades. As mudanças devem ser realizadas de maneira organizada, buscando o melhor desempenho organizacional e a adaptação dos processos em execução [2]. As organizações adotam uma abordagem estratégica para seleção de seu portfólio de projetos, direcionando para o atual cenário do mercado. A correta seleção do portfólio de projetos oportuniza a busca dos objetivos estratégicos, utilizando os recursos disponíveis de maneira adequada [8]. O sucesso estratégico da organização está diretamente atrelado à gestão eficiente de seu portfólio de projetos. Um portfólio desequilibrado em relação à alocação de recursos, com priorização inadequada e sem uma periodicidade de revisão previamente definida, pode direcionar a organização a uma direção contrária ao objetivo buscado, impactando seriamente o futuro da organização [9].

As organizações utilizam as práticas de gerenciamentos de projetos com o objetivo de efetivar uma estratégia baseada em estudos, cenário de mercado, novos entrantes e, com a constante evolução global, surge à necessidade de controle e direcionamento para manter a competitividade [10]. Em relação ao propósito do projeto, a mudança estratégica no escopo pode afetar diversas metas previamente estabelecidas, como custo e prazo, sendo necessário um estudo sobre os possíveis resultados e adequação ou não a realidade da organização [11]. Os projetos em execução são afetados constantemente por mudanças estratégicas, tendo em vista que seu propósito é relacionado a algum objetivo projetado, e a metodologia utilizada para adequação é um fator importante nas organizações [12]. As mudanças na execução dos projetos podem acontecer em qualquer fase do projeto, afetando resultados, cronogramas, prazos e, possivelmente, seu objetivo [13].

Diante desse contexto, surge a pergunta de pesquisa que norteia esse trabalho: quais os impactos que a mudança de estratégia traz para a gestão dos projetos? Para responder essa pergunta este trabalho tem como objetivo analisar os impactos que a mudança de estratégia de uma organização traz para a gestão de projetos, através de um estudo de caso realizado em uma empresa do ramo químico e petroquímico.

\section{Referencial teórico}

Esta seção aborda o referencial teórico em relação aos temas selecionados neste estudo: gestão estratégica, gestão de portfólios de projetos e gestão de projetos.

\subsection{Gestão estratégica}

A estratégia pode ser definida como uma competição, na qual todos procuram encontrar a meta estabelecida. Pode ser caracterizado como a busca para resolução de um problema ou uma vantagem econômica, baseado no que deve ser feito ou não, para alcançar seus objetivos [14]. Os objetivos estratégicos das organizações surgem a partir de oportunidades no seu ramo de negócio, com o propósito de inovação e competitividade [15]. 


\section{REVISTA}

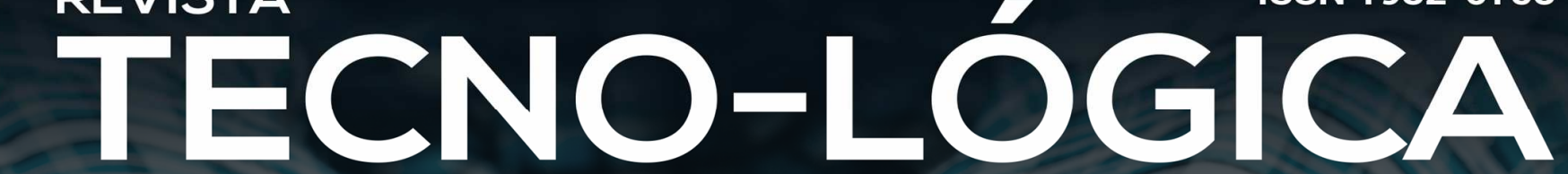

Edição Especial com publicação de trabalhos selecionados do V SIGEPRO

Cada organização define sua estratégia em função de seus produtos, e a mudança de cenário de mercado impulsiona seu direcionamento [16].

O planejamento estratégico das organizações é caracterizado pela sua estrutura organizacional e possibilidade de mercado [17]. A partir do planejamento estratégico, organizações utilizam projetos para geração dos resultados projetados. Projetos são realizados visando à efetivação das estratégias competitivas [18]. Comumente, as empresas desenvolvem um portfólio com diferentes projetos, priorizando conforme cenário e oportunidade de mercado [19]. A criação de um projeto surge a partir da necessidade ou planejamento estratégico da organização, e o entendimento claro do que se busca é estritamente necessário para projetar metas e escopo para execução [20].

\subsection{Gestão de portfólio de projetos}

Estrategicamente, as empresas necessitam definir quais serão as ações necessárias para atingir seus objetivos e metas estipuladas. A conquista dos objetivos estratégicos está atrelada ao objetivo de cada projeto, caracterizando a qualidade do seu portfólio [21]. O Gerenciamento de Portfólio de Projetos (PPM) está relacionado diretamente com o avanço da estratégia através da definição dos critérios estabelecidos e descrição dos recursos necessários para execução dos planos [22].

O gerenciamento de portfólio engloba o planejamento realizado pela organização para atingir seus objetivos, idealizados em projetos que serão realizados conforme estratégia [19]. Com a constante mudança do mercado competitivo, novos projetos deverão ser inseridos ao portfólio para garantir a evolução constante, e projetos vinculados a planos anteriores devem ser revistos e adaptados, caso seja necessário [23]. Caso existam projetos que fujam dos objetivos estratégicos em cada mudança de cenário, a reavaliação é importante e, caso seja necessário, o congelamento ou cancelamento devem ser avaliados [20].

\subsection{Gestão de projetos}

Projeto é definido como um empreendimento que possui características particulares, com uma prévia definição de seu ciclo, conduzido por pessoas para atingir objetivos e parâmetros, com constante acompanhamento e avaliação de suas etapas [22]. Segundo [2], “Administração do projeto é o esforço no sentido de melhor alocar os recursos da empresa, tendo em vista alcançar os objetivos estabelecidos".

O planejamento em relação ao escopo de realização de um projeto deve ser realizado de maneira clara, com um detalhamento prévio de execução de cada etapa e acompanhamento em cada fase [24]. O Sucesso na execução de um projeto é determinado quando os custos identificados no fim do projeto são aproximados em relação ao orçamento inicial, os prazos estipulados no escopo são cumpridos e os resultados correspondem às expectativas dos clientes [31].

Os projetos contidos no portfólio seguem um objetivo em comum com a estratégia da organização e, consequentemente, existindo mudanças de estratégia deverá haver uma revisão, readaptando os projetos que fujam do planejamento atual [24]. O conflito na seleção dos projetos para o portfólio é algo a ser administrado, levando em conta as principais áreas de impacto e objetivo prospectado [25].

\section{Metodologia}

Para condução da pesquisa, é necessário elaborar uma estratégia para desenvolvimento do trabalho. Este trabalho teve como base o modelo proposto por [26], estruturado no modelo de um pêndulo, conforme Figura 1, que ilustra as etapas e fluxo a ser desenvolvido na pesquisa. 

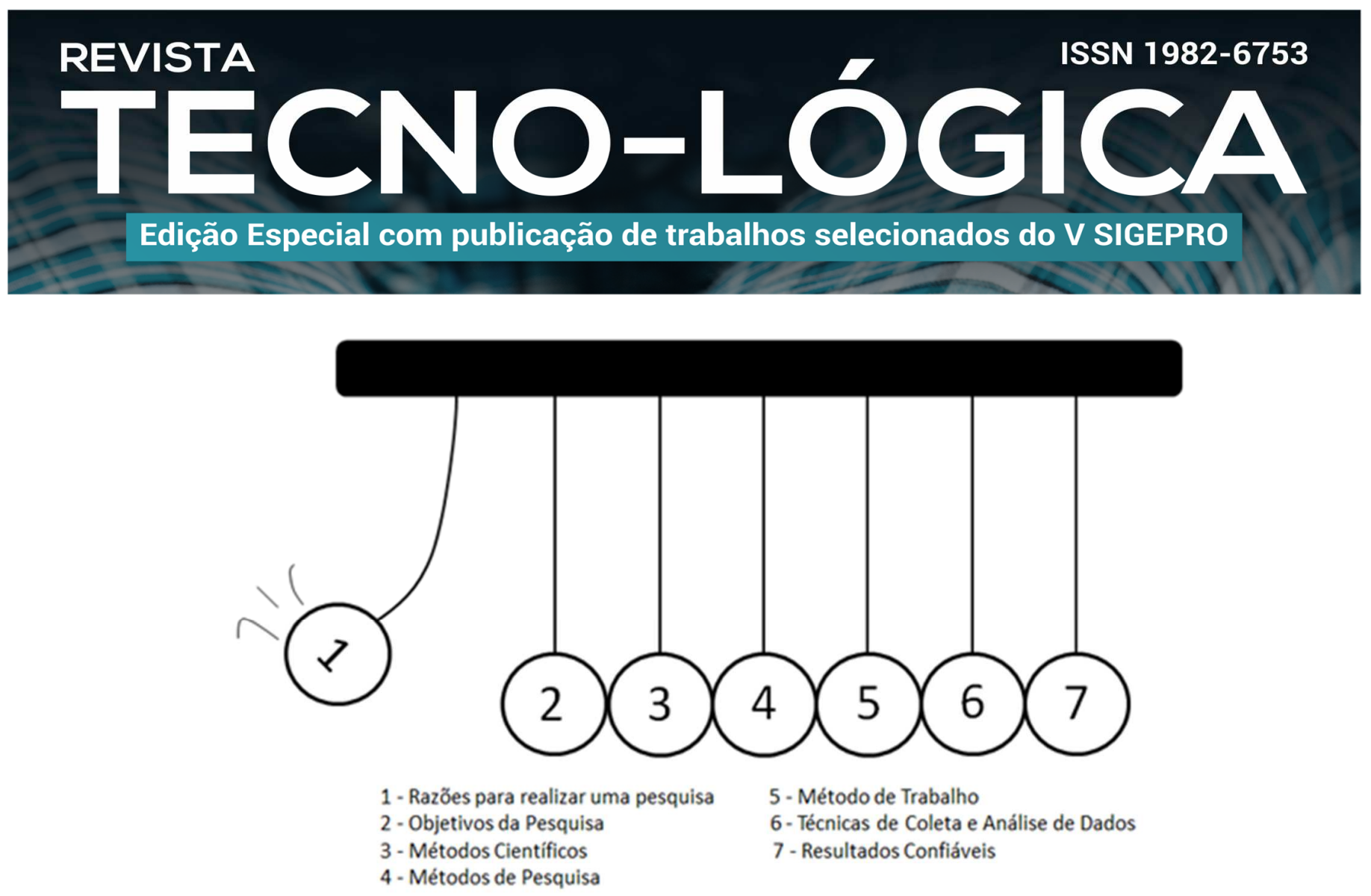

Figura 1- Método para condução da pesquisa [26].

Fase 1: Razões para realizar uma pesquisa: essa pesquisa teve o caráter prático, tendo em vista que identificou as ações realizadas pelos operadores de projeto conforme estratégia da organização, por isso foi definida como pesquisa aplicada.

Fase 2: Objetivos da pesquisa: $O$ objetivo desta pesquisa era analisar os impactos que a mudança de estratégia de uma organização traz para a gestão de projetos.

Fase 3: Escolha do método científico: O método científico utilizado para elaboração da pesquisa foi o indutivo. A indução é caracterizada pela validação e consolidação de dados particularmente coletados, partindo de um estudo amplo em comparação direta com a bibliografia em si [27].
Fase 4: Métodos de pesquisa: o método escolhido para embasamento deste trabalho é o estudo de caso, investigando as relações existentes entre esses cenários e avaliando sua complexidade. Esse método é concretizado através de uma combinação de ferramentas para coleta de dados, com resultados tanto qualitativos como quantitativos [26]. A figura 2 apresenta a estrutura utilizada em estudos de caso.

Etapa 5: Método de trabalho: O método de trabalho pretende detalhar o fluxo realizado para execução da pesquisa, através do método de pesquisa definido anteriormente [26]. O método de trabalho foi definido conforme a estratégia de estudo de caso e é representado pela figura 3. 


\section{REVISTA}

Edição Especial com publicação de trabalhos selecionados do V SIGEPRO

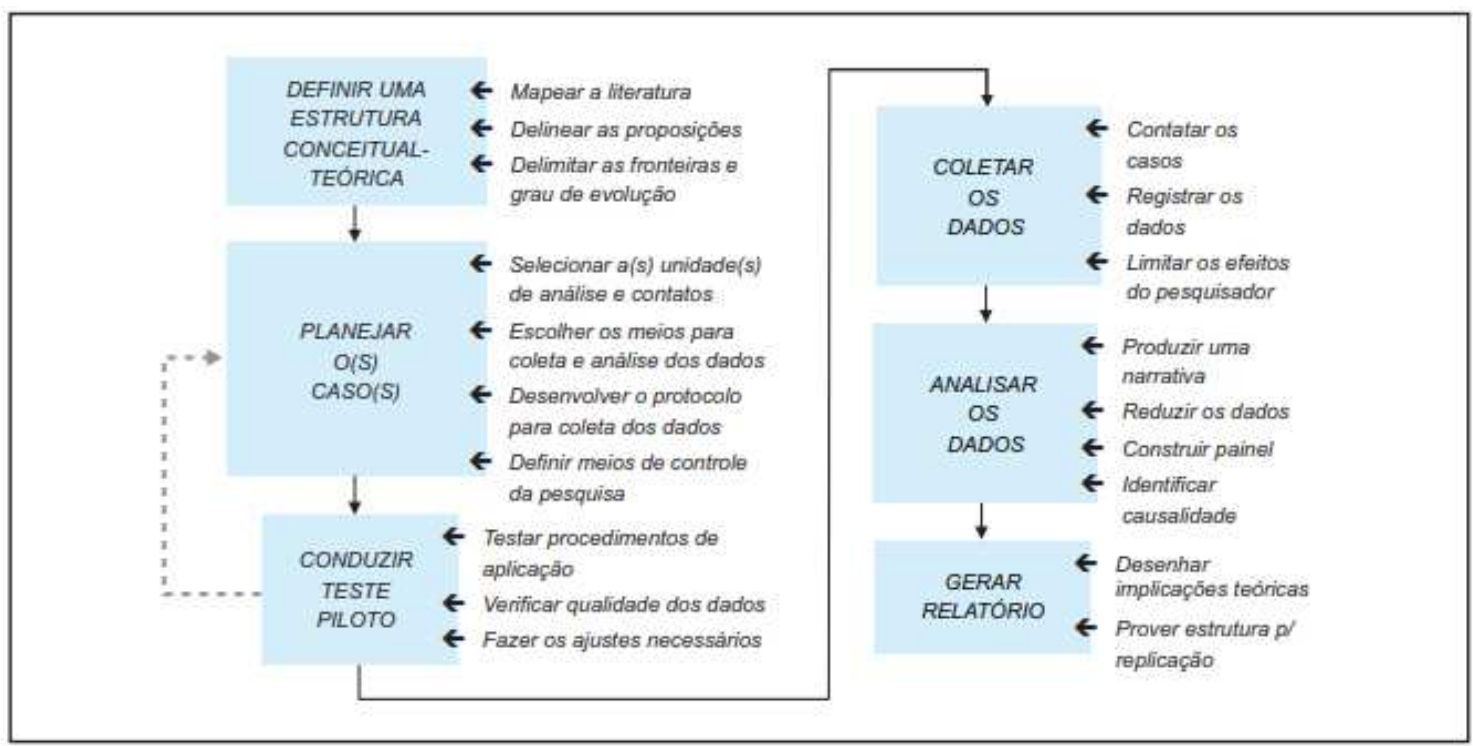

Figura 2- Procedimento do estudo de caso [28]

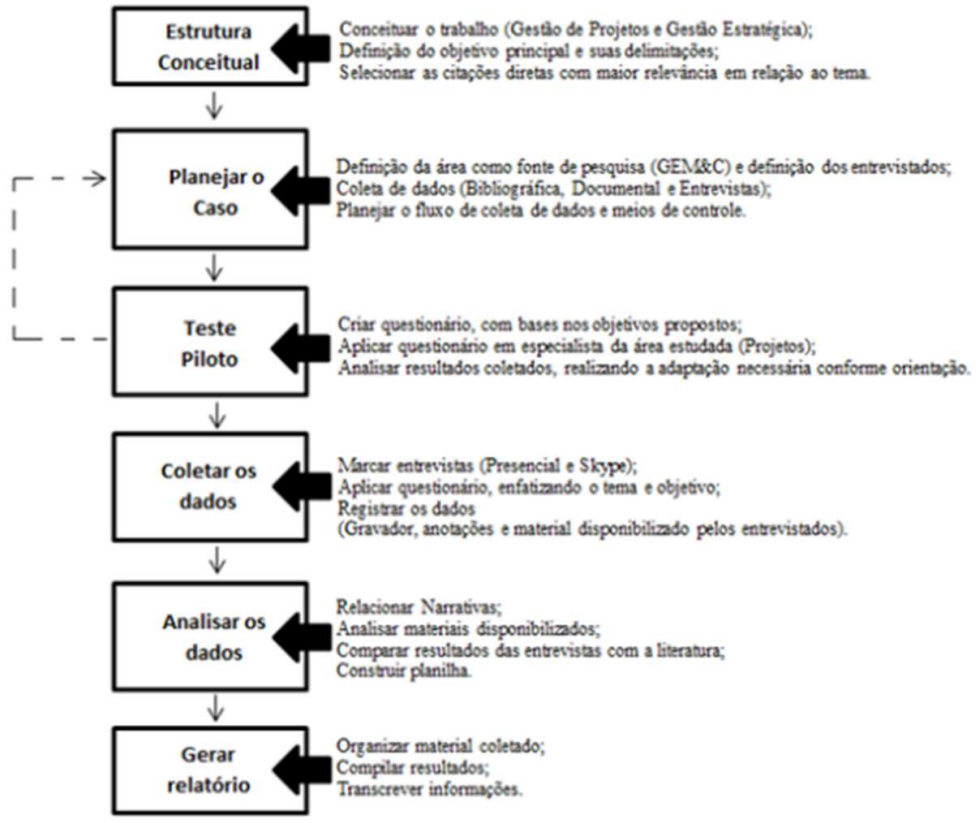

Figura 3 - Fases do método de trabalho. Fonte: elaborado pelos autores (2020). 


\section{REVISTA}

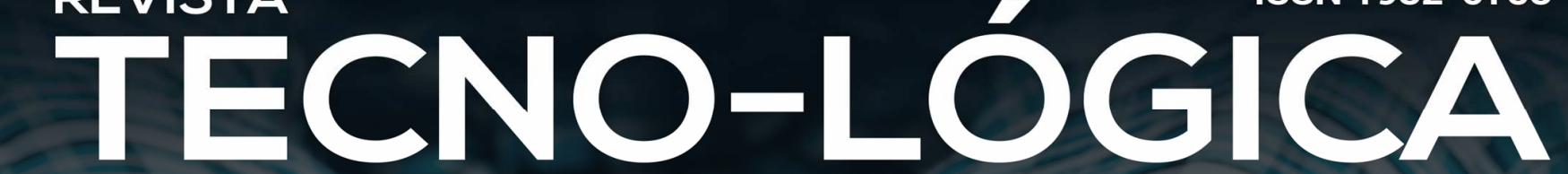

Edição Especial com publicação de trabalhos selecionados do V SIGEPRO

A primeira etapa do método de trabalho trata da construção do embasamento teórico. Esta foi realizada através da construção do referencial teórico, no qual foram abordados os principais tópicos em relação à gestão estratégica, gestão de portfólio de projetos e gestão de projetos. Na sequência foi realizado o planejamento dos casos. Foi selecionada uma empresa do ramo químico e petroquímico, reconhecida no mercado como a maior produtora de resinas termoplásticas das Américas. Dentre as possibilidades, definiu-se para aplicação da pesquisa a área de Gestão Estratégica de Manutenção e Confiabilidade (GEM\&C), que possui uma seção denominada novas tecnologias, responsável pelo estudo e aplicação de projetos que oportunizem melhora nos indicadores de disponibilidade de equipamentos, eficiência de equipamentos, aumento de segurança operacional, dentre outros. Foram definidos como entrevistados 1 engenheiro especialista de novas tecnologias, 1 engenheiro de novas tecnologias e 1 engenheiro de projetos, por serem os profissionais que estão diretamente ligados às etapas de implementação dos projetos. $\mathrm{Na}$ seguinte foi realizado um teste piloto do modelo de coleta de dados, com um profissional com amplo conhecimento em gestão de projetos, certificações e experiências e que atua na empresa a 20 anos, gerenciando projetos em outra área da organização. O objetivo era validar o método de coleta de dados e incluir aspectos importantes que surgiram neste momento. A próxima etapa foi a coleta de dados, seguindo para análise dos dados e finalizando com a geração do relatório, evidenciando os principais pontos abordados que trarão relevo a pesquisa.

Etapa 6: Técnica de coleta e análise de dados: As técnicas utilizadas para coleta de dados foram: bibliográfica, documental e entrevistas. A análise dos dados se deu através do cruzamento das informações dos dados coletados. As entrevistas foram analisadas pela técnica de análise de conteúdo, depois disso foram comparadas com os dados bibliográficos e com a documentação obtida na empresa estudada.

Etapa 7: Resultados confiáveis: Conforme documentos e respostas obtidas pelos entrevistados, procurou-se replicar fielmente as relações abordadas no âmbito da pesquisa e assim obter conclusões relevantes.

\section{Análise dos resultados}

Os resultados foram analisados em três constructos: gestão estratégica, gestão de portifólios e gestão de projetos.

\subsection{Gestão Estratégica}

Estrategicamente a empresa definiu que os projetos são categorizados em três possibilidades: oportunidade de inovação, projetos pontuais e análise de indicadores. Os projetos identificados como oportunidade de inovação são considerados de maior relevância na empresa, estes são criados a partir da identificação de novas técnicas no mercado, provenientes de visitas a feiras, fornecedores e congressos. Os projetos referentes a essa diretriz são inclusos no portfólio no decorrer do ano, efetivados em reuniões trimestrais do grupo.

Projetos pontuais são realizados quando algum contratempo impacta negativamente em alguma área, aplicados em nível de urgência. Os projetos referentes a essa diretriz são inclusos no portfólio no decorrer do ano e efetivados em reuniões trimestrais do grupo. Os projetos referentes à análise de indicadores são inseridos no portfólio na primeira reunião anual e a empresa utiliza esses indicadores para avaliar seu desempenho ao longo do ano, e traçar metas futuras. A gestão de mudança dos projetos conforme planejamento estratégico pode ser aplicado nas 4 principais etapas do pipeline de projetos. A figura 4 apresenta o pipeline dos projetos da organização. 


\section{REVISTA}

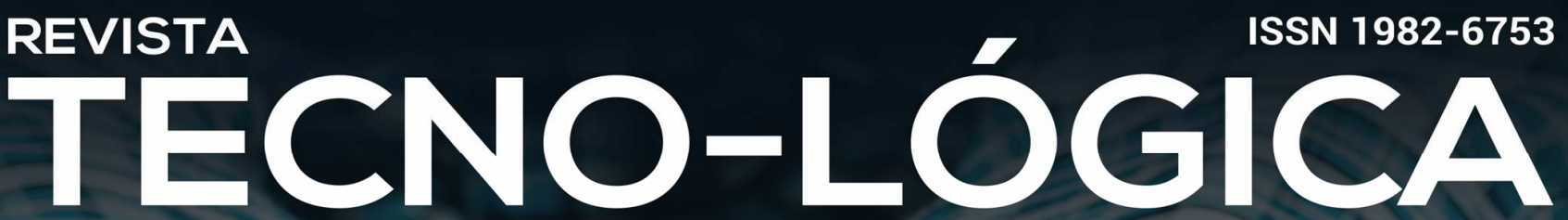

Edição Especial com publicação de trabalhos selecionados do V SIGEPRO

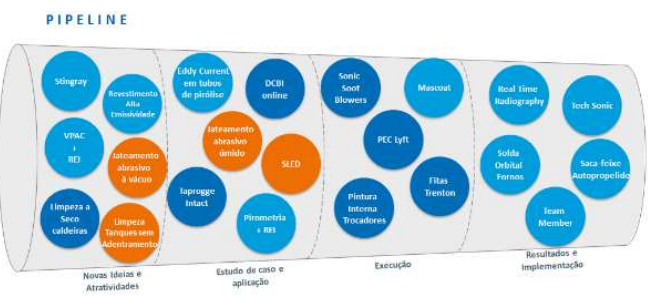

Figura 4 - Pipeline de Projetos. Fonte: Fornecida pela Organização.

Na primeira etapa é realizado o estudo das técnicas com possíveis aplicações conforme estratégia. Se houver mudança estratégica, o projeto é congelado até surgir um novo interesse por parte da organização. Na segunda etapa os projetos já foram aprovados estrategicamente e estão em fase de cadastro de fornecedor, definição de prazos e equipes de trabalho, caso houver mudança estratégica a empresa mantém os projetos no pipeline, mas congela momentaneamente as ações acerca dele. Na etapa de execução dos projetos, a mudança de estratégia impacta em diversas áreas da organização e a necessidade de execução é tratada como prioridade. Na fase de finalização do projeto à mudança estratégica adia a replicação das técnicas para as outras unidades, e o maior impacto é na entrega dos resultados.

A gestão do portifólio é realizada semestralmente. Os projetos são reavaliados e confrontados com a estratégia atual. Diante disso, é definido o congelamento, cancelamento ou continuação. Essa prática corrobora [29] que afirma que os projetos selecionados para o portfólio devem ser analisados ao longo de sua execução, e seus objetivos devem estar atrelados à estratégia da empresa.

\subsection{Gestão de portifólio de projetos}

A empresa utiliza seus projetos tecnológicos para atingir objetivos conforme realidade atual do mercado, e possíveis projeções futuras. A seleção do projeto que será utilizado para atender as possíveis lacunas existentes ou possibilidades de inovação é realizada através de três pilares descritos pela figura 5.

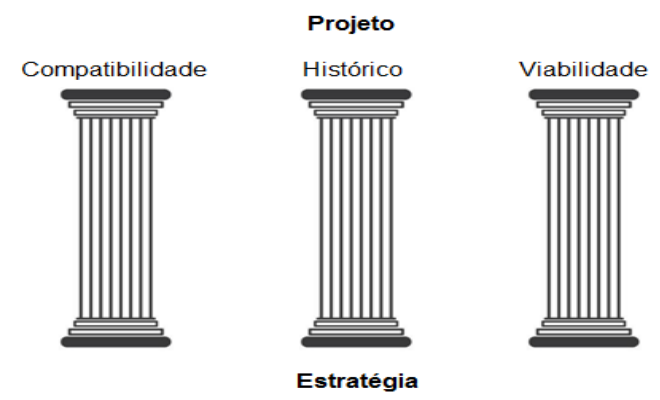

Figura 5 - Seleção de Projetos. Fonte: Elaborado pelos autores (2020).

Inicialmente, é realizada uma análise em relação à compatibilidade do projeto com a estratégia da organização. Em paralelo, é realizada uma análise do histórico do projeto. Por fim, é realizada uma análise de viabilidade, calculando o VPL e outras projeções de custos e investimentos, obtendo uma base sólida para discussão e seleção do projeto. A análise do VPL é fator preponderante para definição dos projetos e é considerado o principal indicador para decisão de investimento. O que converge com [23 - 20] que afirmam que o gerenciamento do portfólio de projetos inclui, além dos planos da organização e programas para alcançar seus objetivos, uma análise do resultado que o projeto gerará conforme estratégia. Deve ser analisado o impacto estratégico que os projetos selecionados causam na organização, e a avaliação auxilia na seleção e mensuração dos resultados projetados com a execução dos planos.

Ao final de cada etapa de execução do pipeline, é realizada uma análise das etapas consolidadas e possíveis contratempos que podem influenciar nas próximas fases, de forma a garantir o sucesso projetado. Esse achado corrobora [30] que colocam que os projetos devem ser acompanhados ao longo se sua execução, assegurando o objetivo estratégico definido na etapa de seleção. À medida que os resultados de cada área são relatados, 


\section{REVISTA}

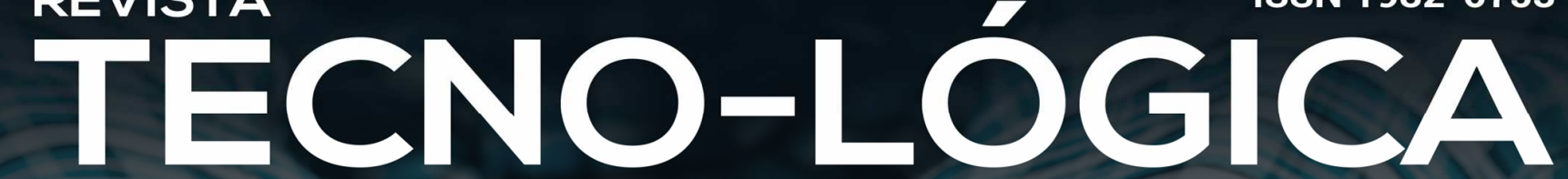

Edição Especial com publicação de trabalhos selecionados do V SIGEPRO

possíveis planos de ação são criados para adequá-los, quando necessário. Esses planos de ação podem interferir na estratégia atual e quando isso acontece é realizada uma análise do portfólio. Nessa nova análise o status dos projetos podem sofrer alteração e eles podem passar para status de obrigatório, congelado ou cancelado.

\subsection{Gestão de portifólio de projetos}

A atualização dos projetos é realizada através de reunião trimestral. O pipeline de projetos possui os hold points a serem executados em cada etapa do projeto, conforme Figura 6, com o intuito de padronizar o fluxo de trabalho.

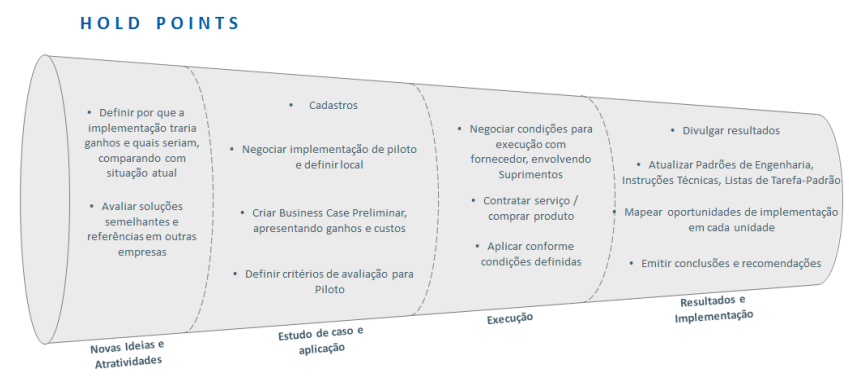

Figura 6 - Hold Points de Projeto. Fonte: Fornecida pela Organização. Fonte: Elaborado pelos autores (2020).

O escopo padrão das atividades do projeto é definido pelos hold points, porém, as etapas de implantação podem sofrer alteração de acordo com cada projeto. Quando é detectado algum desalinhamento do projeto, relacionado à estratégia, são realizadas reuniões internas com os principais envolvidos. Conforme [20] ações corretivas são necessárias quando se observa desvios relacionados ao objetivo do projeto, com uma análise estratégica do planejamento preestabelecido.

De acordo com [23] a área de gestão de riscos atua normalmente na análise dos possíveis impactos suscetíveis aos projetos, para posterior controle pelas equipes responsáveis por etapa, minimizando as consequências negativas. A empresa possui um fluxo de para administrar possíveis mudanças no cenário de cada projeto, padronizando as ações nos hold points e programando com foco na minimização dos impactos, convergindo com a literatura. $\mathrm{Na}$ readaptação, os fatores preponderantes são prazo de entrega e disponibilidade da tecnologia. Qualquer readaptação do projeto busca, primeiramente, o melhor prazo de entrega e disponibilidade para a operação, tendo em vista que possíveis planos já estão sendo direcionados ao fim de cada projeto, e o retorno de investimentos e análise dos resultados provém desses dois fatores.

Com o intuito de determinar as possíveis características que cada projeto necessita, padronizar as equipes atuantes e direcionar especialistas de cada área, os projetos implementados pelo setor são divididos em quatro grupos de projetos, denominados productivity increase, scope reduction, access improvement e exposure reduction. Os projetos são distribuídos nos grupos e a seleção dos projetos e alocação de recursos é direcionada conforme estratégia da organização. Conforme [25] a mudança estratégica implica em definições de novas prioridades na organização, restabelecendo o foco atual e direcionando seus recursos em prol da do sucesso. De acordo com [14] os projetos relacionados no portfólio podem sofrer impactos quando são submetidos a mudanças, principalmente em relação ao escopo estabelecido em suas fases de execução, exemplificando como possíveis danos os custos e cronograma. A empresa possui histórico com problemas referentes a mudanças de escopo, surgidas a partir da readaptação de seus projetos. Os problemas encontrados na organização refletem os fatos apresentados na literatura.

\subsection{Discussões}

O quadro 1 (Apêndice A) apresenta uma relação entre as referências da literatura e os resultados da pesquisa. 


\section{REVISTA}

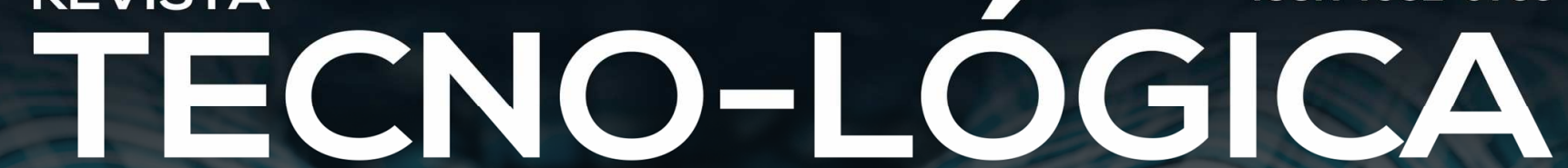

Edição Especial com publicação de trabalhos selecionados do V SIGEPRO

\section{Conclusões}

Essa pesquisa tratou do tema gestão de projetos, buscando responder quais os impactos que a mudança de estratégia traz para a gestão dos projetos. Para isso, foi delineado um estudo de caso em uma empresa do ramo químico e petroquímico, que possui a prática de gestão de projetos para alcançar objetivos específicos e replaneja suas estratégias em função dos cenários do mercado, combinação necessária para analisar o fenômeno sob estudo.

O estudo de caso possibilitou identificar que a empresa estudada relaciona atrasos no prazo de entrega de projetos, reprogramação de equipes, cumprimento de metas das equipes de processo e custos aos impactos provenientes de mudanças estratégicas. Não foi possível identificar estudos quantitativos em relação aos impactos que a mudança de estratégia causa nos projetos, justificado pela falta de controle que a organização tem sobre esses elementos. $\mathrm{O}$ estudo desses elementos poderia indicar o quanto à organização perde em função da mudança, provocando um estudo mais amplo desse cenário e até mesmo a criação de grupos de apoio, responsáveis pela análise precedente a possíveis mudanças conforme objetivo de cada projeto.

Como lacuna de pesquisa identificada, o estudo aplicado poderia ser estendido a outras áreas da organização que possuem interface com gestão de projetos, bem como outras empresas, possibilitando uma análise de quais os impactos dessa metodologia de gestão em outros contextos.

Através desta pesquisa foi possível identificar os impactos que a mudança de estratégia causa na gestão de projetos em uma organização, evidenciando os métodos praticados para preservar a competitividade nos negócios e progresso do planejamento estratégico. A pesquisa em si trouxe possibilitou uma visão correlacionada entre as práticas gerenciais da organização e elementos da literatura, ressaltando a importância de uma análise prévia dos objetivos estratégicos relacionados à gestão de projetos.

IMPACT OF STRATEGY CHANGE ON PROJECT

\section{MANAGEMENT: CASE STUDY IN A PETROCHEMICAL COMPANY}

ABSTRACT: The search for competitiveness and innovation is becoming increasingly important in the current scenario. Project Management and Strategic Planning are commonly associated with organizations, and the misalignment between the parties can lead to unproductive results. Strategic changes become necessary when the competitive scenario leads to new market opportunities. However, previous plans are under development, and the correct adaptation seeks to cause the least impact between Project Management and Change. The work aims to analyze the impacts that an organization's strategy change brings to project management. For this, a case study was carried out in a chemical and petrochemical company. Through this research, it was possible to identify the impacts that the change of strategy causes in project management in an organization and the approaches used to minimize the adverse effects. Periodic meetings, analysis of the project objective at the end of each stage of the pipeline, and study of the project's compatibility with the strategy are approaches used by the company to minimize impacts. Problems related to delays in delivery times, rescheduling of teams, compliance with process team goals, and costs are characteristics affected by the change in strategy.

Keywords: Project Management. Portfolio Management. Strategic Planning. Strategic Projects. 


\section{REVISTA}

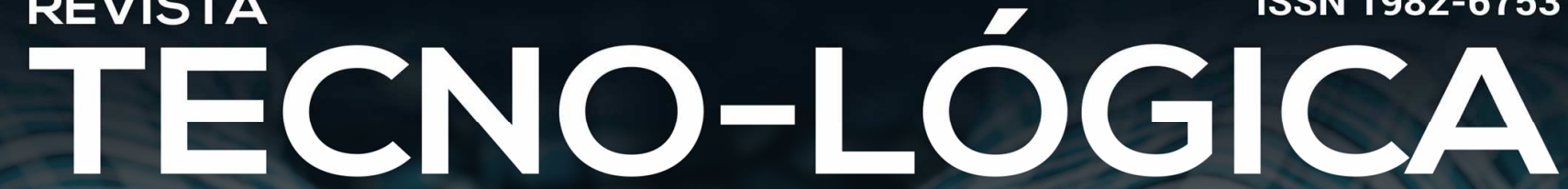

\section{Edição Especial com publicação de trabalhos selecionados do V SIGEPRO}

\section{REFERÊNCIAS}

[1] ALMEIDA, K. T. D. Planejamento estratégico e metodologia de gerenciamento de projetos: uma vantagem competitiva para as empresas. Revista Techoje, Belo Horizonte: 2010.

[2] OLIVEIRA, D. P. R. Planejamento estratégico: conceitos, metodologias e práticas. 28. ed. São Paulo: Atlas, 2010

[3] KUAZAQUI, E. Planejamento Estratégico. São Paulo: Cengage, 2016.

[4] SRIVANNABOON, S.; MILOSEVIC, D. Z. A two-way influence between business strategy and project management. International Journal of Project Management. v. 24, 2006.

[5] MELlO, A. M.; MARX, R. Contribuição aos critérios de projeto organizacional para inovação na indústria petroquímica brasileira. Gest. Prod. São Carlos, v. 20, n. 2, 2013

[6] MORRIS, P. W. G.; JAMIESON, A. Translating corporate strategy into project strategy. Project Management Institute; 2004. 228.

[7] SILVA JÚNIOR, O. F. P.; SIEDSCHLAG, D.; ALVES, C. S. R. A estratégia, seleção de projetos e escritório de gestão de projetos: O caso de uma universidade comunitária. IV SINGEP, Simpósio internacional de Gestão de Projetos, Inovação e Sustentabilidade. São Paulo - SP - Brasil, 2015. Disponível em: https://singep.org.br. Acesso em: 07 mar 2020.

[8] CARVALHO, M. M.; LOPES, P. V. B. V. L.; MARZAGÃO, D. S. L. Gestão de Portfólio de Projetos: Contribuições e Tendências da Literatura. Gest. Prod. São Carlos, v. 20, n. 2, 2013.

[9] PRADA, C. A.; ABREU, A. F.; ABREU, P. F.; TRZECIAK, D. The importance of innovation projects portfolio review for organizations. E-Tech: Tecnologias para Competitividade Industrial, Florianópolis, v. 2, n. 1, 2009. Disponível em: https: etech.sc.senai.br. Acesso em: 08 abr 2020.

[10] RODRIGUES, R.; PAIXÃO, C. H. A importância de planejamento estratégico na gestão de projetos. XII congresso nacional de excelência em gestão \& III INOVARSE - Responsabilidade social aplicada. 2016. Disponível em: http://www.inovarse.org/sites/default/files/T16 274.pdf. Acesso em: 18 abr 2020.

[11] PORTILLO, C. A. Gerenciamento eficaz do escopo do projeto. Livraria Virtual. PMI, 2010.
[12] PATAH, L. A.; CARVAlho, M. M. Métodos de Gestão de Projetos e Sucesso dos Projetos: Um estudo quantitativo do relacionamento entre estes conceitos. Revista de Gestão e Projetos - GeP. São Paulo, v. 3, n. 2, 2012.

[12] PMI - Project Management Institute. 5. ed. 2013.

[13] SCHOONWINKEL, S.; FOURIE, C. J.; CONRADIE, P. D. F. A risk and cost management analysis for changes during the construction phase of a project. Journal of the South African Institution of Civil Engineering. v. 58, n. 4, 2016.

[14] PORTER, M. Estratégia Competitiva: técnicas para análise de indústrias. Rio de Janeiro: Campus, 2005

[15] BORGES, J. G.; CARVALHO, M. M. Critérios de sucesso em projetos: Um estudo exploratório considerando a interferência das variáveis tipologia de projetos e Stakeholders. Production, v. 25, n. 1, 2015.

[16] MALDANER, L. F.; KRELING, R. Strategic Management of Manufacturing - Proposal of a method that recommends Production Techniques to Leverage Different Competitive Dimensions. Brazilian Business Review, 2018.

[17] NEIS, D. F.; PEREIRA, M. F.; MACCARI, E. A. Strategic Planning Process and Organizational Structure: Impacts, Confluence and Similarities. Brazilian Business Review, 2016.

[18] JUNIOR, L. J. M.; PLONSKI, G. A. Gestão de projetos em empresas no Brasil: abordagem "tamanho único"?. Gest. Prod. São Carlos, v. 18, n. 1, 2011.

[19] VALLE, A. B.; SOARES, C. A. P.; FINOCCHIO JR, J.; SILVA, L. S. F. Fundamentos do Gerenciamento de Projetos. Rio de Janeiro: FGV, 2010.

[20] HELDMAN, K. Gerência de projetos. 5 ed. Rio de Janeiro: Elsevier, 2009.

[21] SOUZA, P. B.; CARNEIRO, J.; MELLO, R. B. Estudo sobre as Dimensões Conceituais da Gestão de Portfólio de Projetos. BBR Special Issues. Vitória-ES, 2015.

[22] CASTRO, H. G.; CARVAlHO, M. M. Gerenciamento de Portfólio de Projetos (PPM): estudos de caso. São Paulo: 2009.

[23] CAVAlCANTI, F. R. P.; SILVEIRA, J. A. N. Fundamentos de gestão de projetos: gestão de riscos. São Paulo: Atlas, 2016.

[24] WU, D.; DAI, Q.; ZHU, X. Measuring the effect of Project risks based on Shapley value for project risk response. Procedia Computer Science, v. 91, 2016.

[25] MENEZES, L. C. M. Gestão de Projetos: com abordagem dos métodos ágeis e híbridos. 4. ed. São Paulo: Atlas, 2018. 


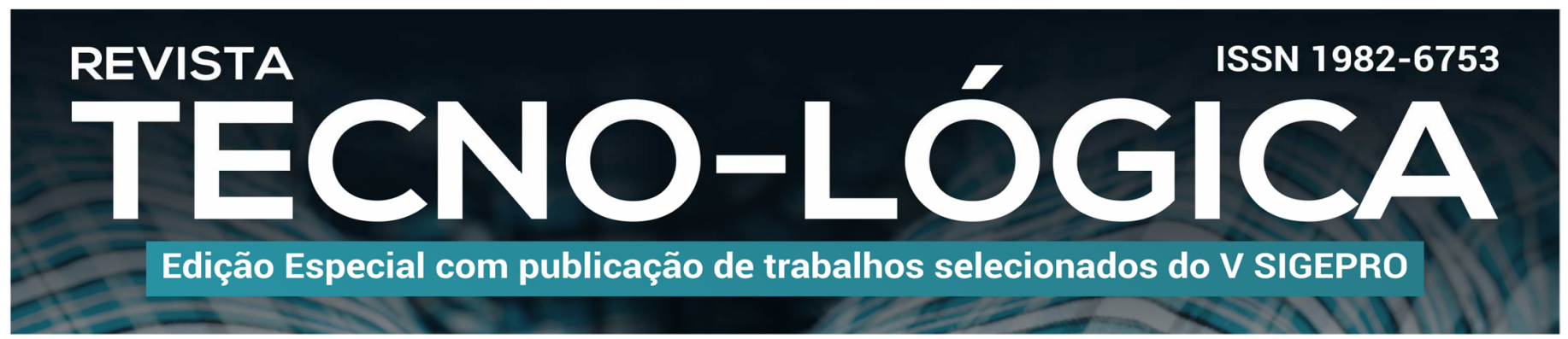

[26] DRESCH, A.; LACERDA, D. P.; ANTUNES JR, J. A. V. Design Science Research Método de Pesquisa para avanço da ciência e tecnologia. Porto Alegre: Bookman, 2015.

[27] MARCONI, M. A.; LAKATOS, E. M. Metodologia científica. 7. ed. São Paulo: Atlas, 2017.

[28] CAUCHICK MIGUEL, P. A. Estudo de caso na engenharia de produção: estruturação e recomendações para sua condução. Produção, v. 17, n. 1, p. 216-229, jan./abr. 2007. Disponível em: http://www.scielo.br/pdf/prod/v17n1/14.pdf. Acesso em: 20 maio 2019.

[29] NASCIMENTO, P. T. S. Gestão da produção e operaçães: bases para competitividade. São Paulo: Atlas, 2014.

[30] CASSIANO, A. D. P.; ABDOLLAHYAN, F. Gerenciamento de portfolio de projetos alinhado aos objetivos estratégicos por meio do Balanced Scorecard. SEGeT - Simpósio de Excelência em Gestão e Tecnologia. 2008. Disponível em: https://administradores.com.br/producao-academica/gerenciamento-de-portfoliode-projetos-alinhado-aos-objetivos-estrategicos-por-meio-do-balanced-scorecard. Acesso em: 12 abr 2020.

[31] BERSSANETI, F. T.; CARVALHO, M. M. Identification of variables that impact project success in Brazilian companies. International Journal of Project Management, v. 33, n.1, p. 638-649, 2015. 


\section{REVISTA}

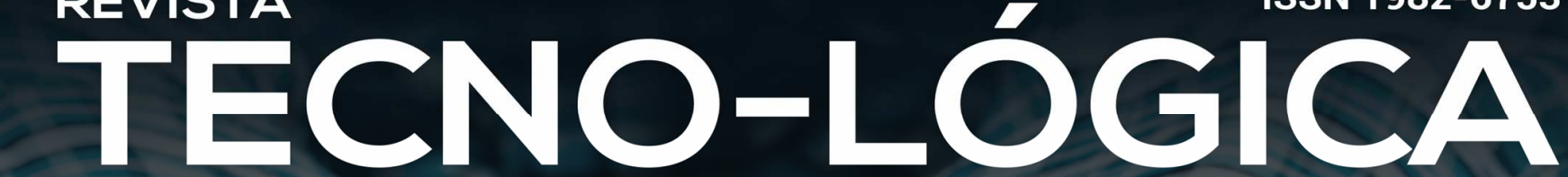

Edição Especial com publicação de trabalhos selecionados do V SIGEPRO

\section{APÊNDICE A}

Quadro 1 - Discussão dos resultados.

\begin{tabular}{|c|c|c|}
\hline Tema & Revisão da literatura & Resultados da pesquisa \\
\hline \multirow[t]{2}{*}{$\begin{array}{l}\text { Gestão } \\
\text { Estratégica }\end{array}$} & $\begin{array}{l}\text { "A carteira de projetos selecionada para execução } \\
\text { conforme estratégia deverá ser revista ao longo de } \\
\text { sua execução. Em paralelo, projetos oriundos de } \\
\text { planos anteriores também deverão ser revistos, } \\
\text { para validar o esforço investido". [29]. }\end{array}$ & $\begin{array}{l}\text { A organização possui um pipeline de projetos, contendo as } \\
\text { quatro etapas que configuram o desenvolvimento dos projetos, } \\
\text { e cada etapa possui sua particularidade em relação ao impacto } \\
\text { de mudança de estratégia. Na etapa inicial, denominada como } \\
\text { Novas Ideias e Atratividades, a mudança de estratégia não } \\
\text { causa nenhum impacto significativo. Na segunda etapa, } \\
\text { denominada estudo de caso e aplicação, mudanças de estratégia } \\
\text { congelam o avanço da tecnologia, com prioridade de discussão } \\
\text { no próximo encontro dos grupos. Na terceira etapa, que } \\
\text { consiste na execução dos projetos, a mudança de estratégia } \\
\text { impacta em diversas áreas da organização, resultando em } \\
\text { reuniões emergenciais para discussão. Na última etapa, } \\
\text { definida como Resultados e Implementação, a mudança de } \\
\text { estratégia não ocasiona nenhum impacto relevante na } \\
\text { organização, apenas atrasa a divulgação dos resultados para a } \\
\text { empresa. A área pesquisada possui três direcionamentos para } \\
\text { seleção de projetos conforme estratégia, que são Oportunidade } \\
\text { de inovação, Projetos Pontuais e Análise de Indicadores. Os } \\
\text { projetos são analisados semestralmente, em reuniões entre as } \\
\text { equipes envolvidas, avaliando o portfólio como um todo e } \\
\text { efetivando possíveis resultados conforme estratégia. }\end{array}$ \\
\hline & $\begin{array}{l}\text { "Caso não haja projetos para alguma orientação } \\
\text { estratégica ou vice-versa, identificam-se as lacunas } \\
\text { estratégicas e os projetos desalinhados. Se não há } \\
\text { projetos atendendo a alguma orientação } \\
\text { estratégica, é o caso de solicitar a preparação de } \\
\text { novos projetos ou a modificação de existentes para } \\
\text { atendê-la". [29] }\end{array}$ & $\begin{array}{l}\text { Nas reuniões semestrais, são avaliados todos os projetos do } \\
\text { portfólio e, caso ocorra alguma mudança estratégica, os } \\
\text { projetos em execução podem ser cancelados, congelados ou } \\
\text { readaptados. A organização não possui uma metodologia } \\
\text { padrão de reestruturação, o que justificação a avaliação } \\
\text { individual de cada cenário. }\end{array}$ \\
\hline \multirow{2}{*}{$\begin{array}{ll}\text { Gestão } & \text { de } \\
\text { Portfólio } & \text { de } \\
\text { Projetos } & \end{array}$} & $\begin{array}{l}\text { "O gerenciamento de portfólios abrange o } \\
\text { gerenciamento da coleção de programas, projetos, } \\
\text { outros trabalhos e ás vezes outros portfólios. Isso } \\
\text { inclui a comparação do valor do projeto real ou } \\
\text { potencial com os objetivos estratégicos do } \\
\text { negócio". [11]. }\end{array}$ & $\begin{array}{l}\text { A seleção do projeto que será utilizado para atender as possíveis } \\
\text { lacunas existentes ou possibilidades de inovação é realizada } \\
\text { através de três pilares, que são compatibilidade com a } \\
\text { estratégia, viabilidade de investimento e histórico de aplicação } \\
\text { das técnicas. A correlação entre esses aspectos são } \\
\text { indispensáveis para a correta seleção e continuidade no pipeline } \\
\text { da área. }\end{array}$ \\
\hline & $\begin{array}{l}\text { "[...] o gerenciamento de portfolio de projetos deve } \\
\text { gerir os programas e projetos dentro da } \\
\text { organização, pois cada vez, mais e mais projetos } \\
\text { são iniciados e estão em curso, havendo uma } \\
\text { necessidade em se manter o foco no conjunto e } \\
\text { assegurar que todos estejam contribuindo com os } \\
\text { objetivos estratégicos". [30] }\end{array}$ & $\begin{array}{l}\text { Todos os projetos do portfólio possuem seu objetivo específico, } \\
\text { e a análise de qualquer aleatoriedade que possa interferir no } \\
\text { resultado projetado conforme estratégia é realizada no final de } \\
\text { cada etapa de execução. }\end{array}$ \\
\hline
\end{tabular}




\section{REVISTA}

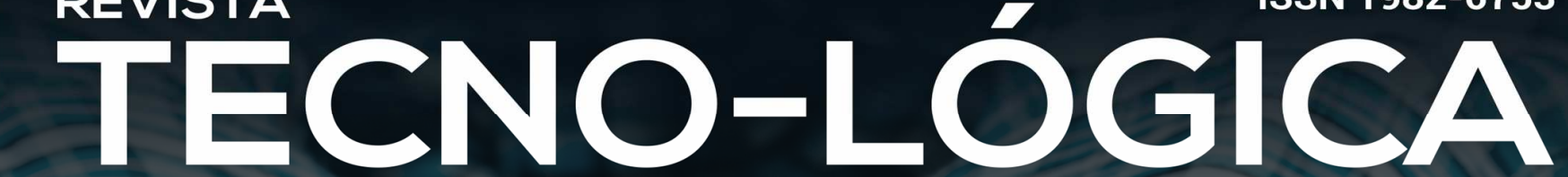

Edição Especial com publicação de trabalhos selecionados do V SIGEPRO

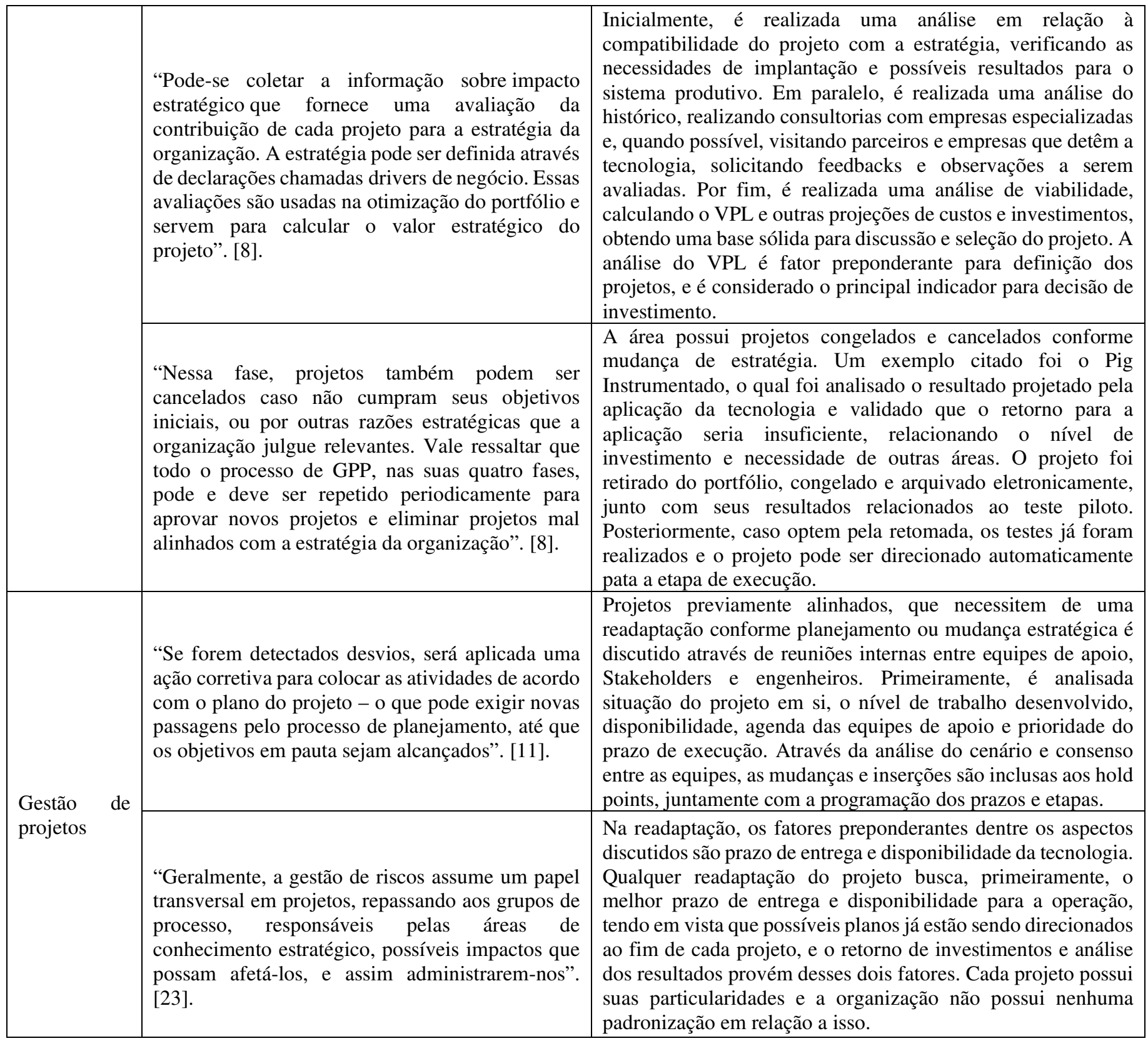




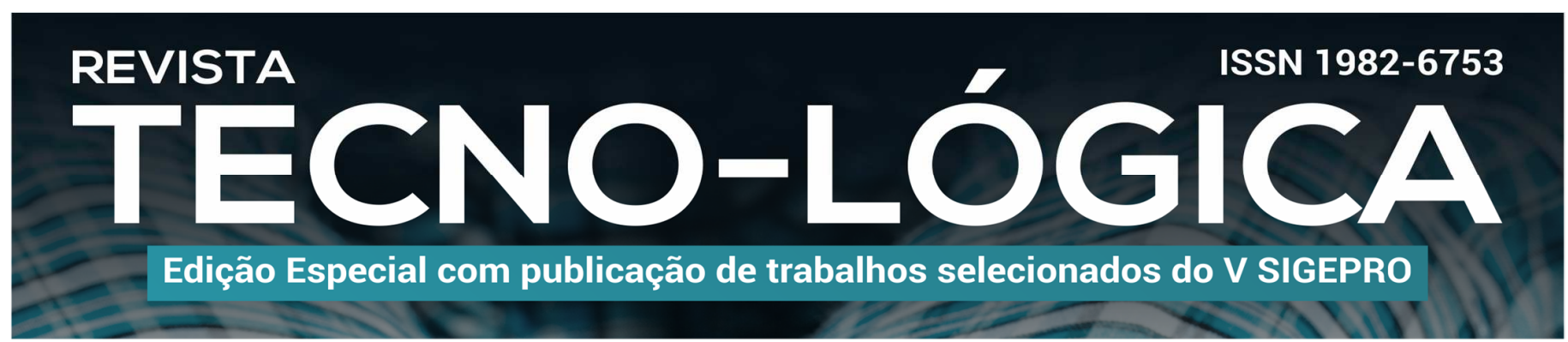

\begin{tabular}{|c|c|c|}
\hline & $\begin{array}{l}\text { "Os conflitos sobre estabelecimento de } \\
\text { prioridades são aqueles que ocorrem em razão de } \\
\text { mudanças na organização - interna ou externa ao } \\
\text { projeto. Competindo por recursos escassos ou } \\
\text { procurando estabelecer determinados "focos" entre } \\
\text { seus vários projetos em desenvolvimento, devem } \\
\text { estabelecer - e não raras vezes modificam - } \\
\text { prioridades para atenção nos projetos". [25]. }\end{array}$ & $\begin{array}{l}\text { Com o intuito de determinar as possíveis características que } \\
\text { cada projeto necessite, padronizar as equipes atuantes e } \\
\text { direcionar especialistas de cada área, os projetos } \\
\text { implementados pelo setor são divididos em quatro grupos de } \\
\text { projetos, denominados Productivity Increase, Scope Reduction, } \\
\text { Access Improvement e Exposure Reduction. A prioridade dos } \\
\text { projetos é dividida nesses quatro grupos e os recursos são } \\
\text { planejados em cada um deles. }\end{array}$ \\
\hline & $\begin{array}{l}\text { "Mudanças no escopo do projeto podem impactar } \\
\text { os custos e o cronograma do projeto de maneira } \\
\text { diferente, dependendo de quando essas mudanças } \\
\text { são implantadas no ciclo de vida do projeto". [14]. }\end{array}$ & $\begin{array}{l}\text { Quando as lideranças mudam suas estratégias conforme } \\
\text { cenário, as etapas pré-definidas no projeto sofrem diversos } \\
\text { impactos que incidem sobre a organização. Historicamente, os } \\
\text { problemas relacionados á atraso no prazo de entrega, } \\
\text { reprogramação de equipes, cumprimento de metas das equipes } \\
\text { de processo e custos são características afetadas pela } \\
\text { readaptação de projetos. }\end{array}$ \\
\hline
\end{tabular}

Fonte: elaborado pelos autores (2020). 